\title{
Volatility at Karachi Stock Exchange
}

\author{
ASLAM FARID and JAVED ASHRAF
}

\section{INTRODUCTION}

Frequent "crashes" of the stock market reported during the year 1994 suggest that the Karachi bourse is rapidly converting into a volatile market. This cannot be viewed as a positive sign for this developing market of South Asia. Though heavy fluctuations in stock prices are not an unusual phenomena and it has been observed at almost all big and small exchanges of the world. Focusing on the reasons for such fluctuations is instructive and likely to have important policy implications. Proponents of the efficient market hypothesis argue that changes in stock prices are mainly dependent on the arrival of information regarding the expected returns from the stock. However, Fama (1965), French (1980), and French and Rolls (1986) observed that volatility is to some extent caused by trading itself. Portfolio insurance schemes also have the potential to increase volatility. Brady Commission's Report provides useful insights into the effect of portfolio insurance schemes. It is interesting to note that many analysts consider the so-called "crashes" of Karachi stock market as a deliberate move to bring down prices. An attempt is made in this study to examine the effect of trading on the volatility of stock prices at Karachi Stock Exchange (KSE). Findings of the study will help understand the mechanism of the rise and fall of stock prices at the Karachi bourse.

\section{THE MODEL}

Geometric Brownian Motion is now the most widely used model of stock price behaviour. It has been used in this article to explain the variations in stock prices at the Karachi Stock Exchange (KSE). The underlying assumptions of the model are given below:

(a) The stock price is uncertain and the uncertainty associated with the return from the stock tends to increase with time.

(b) The return from a stock and its variance are functions of time and the stock price itself.

Aslam Farid is Assistant Professor at the Textile University of Pakistan in Karachi. Javed Ashraf is Professor and Vice President at the same institution.

Authors' Note: We wish to express our gratitude to Dr M. Atiqullah (Director, Institute of Statistical Science, Karachi). We are fully responsible for all remaining errors and omissions. 
(c) In practice stock prices are restricted to descrete values and changes can be observed only when exchange is open. However, for modelling purposes, it is not unreasonable to assume that stock prices follow a continuous variable-continuous time-stochastic process.

Under these assumptions, change in the price of a stock over a short interval of time $(d t)$ is given by the stochastic differential equation:

$$
\underline{d} S=\mu S d t+\sigma S d Z \quad \ldots \quad \ldots \quad \ldots \quad \ldots
$$

Where $\mu$ is the expected rate of return from the stock,

$\sigma$ is the volatility of the stock price,

$d Z$ is a random sample from a normal distribution of mean zero and variance $d t$.

The solution of Equation-1 involves the use of stochastic calculus, and with the help of Ito's lemma it can be shown that stock price ' $s$ ' follows a stochastic process given by $S=\{S t: t \geq 0\}$ and price at any time ' $T$ ' can be predicted by the following formula:

$$
S T=\text { So } \operatorname{Exp}\left[\left(\mu-1 / 2 \sigma^{2}\right)+\sigma T W\right] \quad \ldots \quad \ldots \ldots
$$

where $W$ is the standard Brownian motion. Equation-2 shows that stock prices follows a log-normal distribution. The parameters of the distribution, i.e., $\mu \& \sigma$ can be estimated empirically from the historical data. The log-normal property of stock prices implies that change in the price at the end of ith interval is given by $\ln \left(S_{i} / S_{i-}\right.$ $\left.{ }_{1}\right)$, which means the parameter $\sigma$ which captures the stock price volatility can be estimated by finding the standard deviation of $\ln \left(S_{i} / S_{i-1}\right)$ and can be annualised by multiplying it with the square root of the number of trading times in the year.

\section{DATA AND METHODOLOGY}

To study the effect of the volume of trading on the volatility of stock prices, ten companies were randomly selected from the hundred companies enlisted on the KSE-100 Index. The KSE-100 Index is the most widely used indicator of the performance of Karachi's equity market and includes almost all leading companies enlisted by the Karachi Stock Exchange. The average daily turnover of each selected company's shares was calculated from the published data for the first six months of 1994. This average turnover of each company was expressed as a percentage of the total number of shares of that company and was used as an indicator of the volume of trading of each of those companies. 
To estimate the parameters of the model, the closing prices of each company's stock at the end of the week were noted from January to June 1994. Three separate rankings of the selected companies were made on the basis of (i) the volume of trading; (ii) the expected rate of return from the stocks; and (iii) the volatility of each company's stock. The statistical question involved determining whether there was an agreement between the rankings according to (i) the volume of trading and volatility; (ii) the volume of trading and the expected rate of return; and (iii) the expected rate of return and volatility. To answer these questions, Spearman's rank correlation coefficient for each pair of rankings was calculated and standard statistical techniques to test the reliability of the results were employed.

\section{RESULTS}

The Validity of the Model. The general impression about the Karachi Stock Exchange is that prices are normally broker-driven, and the market is highly speculative. Analysts are generally sceptical about the validity of the latest stochastic models at the Karachi Stock Exchange, and cynically remark that changes in the stock prices are not stochastic but deterministic functions of time, and that groups of leading operators control the market. Contrary to this general impression, the results of our study support the assumptions behind the model that the behaviour of stock prices at the Karachi Stock Exchange can be modelled by a time-continuous and continuous-variable stochastic process which has a log-normal distribution, and short-term predictions about the prices can be made by a careful estimation of model parameters. Table 1 lists the actual and predicted values of each company's stock (for the two weeks following June 30, 1994). The actual values were found to be within the 95 percent confidence limits.

Table 1

Actual and Predicted Stock Prices Based on the Model

\begin{tabular}{lccccc}
\hline \multirow{2}{*}{$\begin{array}{l}\text { Name of the } \\
\text { Company }\end{array}$} & $\begin{array}{c}\text { Actual } \\
\text { Price }\end{array}$ & $\begin{array}{c}\text { Predicted } \\
\text { with 95\% C-I }\end{array}$ & & $\begin{array}{c}\text { Actual } \\
\text { Price }\end{array}$ & $\begin{array}{c}\text { Predicted } \\
\text { with 95\% C-I }\end{array}$ \\
\cline { 2 - 3 } \cline { 5 - 6 } Banker's Equity & 46.00 & $44.10-48.30$ & & 44.50 & $42.80-50.50$ \\
Engro Chemicals & 249 & $244-253$ & & 238 & $237-251$ \\
Charat Cement & 120.50 & $119-124$ & & 122 & $118.7-127.3$ \\
P.S.O. & 350 & $346-354$ & & 348 & $346.5-356.1$ \\
ICP Sems & 89 & $86.3-90.5$ & & 89.5 & $85.4-91.5$ \\
Pakland Cement & 128.5 & $125-132$ & & 129 & $121-136$ \\
Pak-Suzuki & 58 & $54.3-60.1$ & & 61 & $55.1-63.4$ \\
Mohib Textile & 17 & $15.3-20.3$ & & 18.5 & $14.8-22.1$ \\
Shell-Pak & 230 & $228-232$ & & 230 & $226.3-231.3$ \\
Stand-Chartered & 78 & $73.5-81.6$ & & 77 & $71.6-83.1$ \\
\hline
\end{tabular}


Volume of Trading and Volatility of Stock Price. Volume is perhaps the most important indicator of the activity in any stock market. Without taking the volume of trading into consideration, any upward or downward fluctuation of the price cannot allow correct analysis of price movements. The volume of trading at Karachi Stock Exchange was found to be quite low as is evident in Table 2. Comparatively, heavy trading was noted in new issues such as ICP( SEMS) and Mohib Exports, whereas Engro Chemicals and Standard Chartered had very low trading. The size of the firm did not seem to have any effect on the volume of trading. Almost perfect positive correlation was found between the volume of trading and the expected rate of return from the stock $\left(r_{v, r}=0.90\right)$. Similarly, strong positive correlation was observed between the volume of trading and volatility $\left(r_{t . v}=0.73\right)$, and also between volatility and expected rate of return $\left(r_{v, r}=0.85\right)$. These results suggest that for the majority of investors at the Karachi Stock Exchange, the decision to buy or sell a particular stock is not based on any financial analysis or professional advice. Instead, the decision to invest in a particular stock is motivated only by the existing trend in price movements, however short-term it may be, and the rate of return from the stock (Tables 2 and 3).

Table 2

Size of Firms, Market Values of Shares, and Average Daily Turnover of Companies Randomly Selected for Study

\begin{tabular}{|c|c|c|c|c|}
\hline \multirow[b]{2}{*}{ Name of Company } & \multirow{2}{*}{$\begin{array}{l}\text { No. of } \\
\text { Shares in } \\
\text { Million }\end{array}$} & \multicolumn{2}{|c|}{ Market Value } & \multirow{2}{*}{$\begin{array}{l}\text { Average Daily } \\
\text { Turnover as \% } \\
\text { of Total Shares }\end{array}$} \\
\hline & & $3-01-94$ & 30-6-94 & \\
\hline Banker’s Equity & 57.025 & 36.00 & 45.50 & 0.083 \\
\hline Engro Chemicals & 41.184 & 297.00 & 253.00 & 0.004 \\
\hline Charat Cement & 38.506 & 110.00 & 140.00 & 0.113 \\
\hline P.S.O. & 37.649 & 390.00 & 390.00 & 0.034 \\
\hline ICP Sems & 28.000 & 62.25 & 79.75 & 0.273 \\
\hline Pakland Cement & 25.000 & 125.00 & 185.00 & 0.091 \\
\hline Pak-Suzuki & 24.566 & 63.50 & 58.00 & 0.049 \\
\hline Mohib Textile & 21.000 & 45.00 & 54.00 & 0.234 \\
\hline Shell-Pak & 13.552 & 235.00 & 205.00 & 0.024 \\
\hline Stand-Chartered & 12.000 & 65.50 & 87.00 & 0.005 \\
\hline
\end{tabular}


Table 3

Ranking of Companies on the Basis of Expected Return, Volume of Trading and Volatility of Stock Prices

\begin{tabular}{lccc}
\hline $\begin{array}{c}\text { Name of the } \\
\text { Company }\end{array}$ & $\begin{array}{c}\text { Ranking Based on } \\
\text { Expected Rate of } \\
\text { Return }\end{array}$ & $\begin{array}{c}\text { Ranking Based on } \\
\text { Volume of Trading }\end{array}$ & $\begin{array}{c}\text { Ranking Based } \\
\text { on Volatility }\end{array}$ \\
\hline Banker's Equity & 2 & 5 & 2 \\
Engro Chemicals & 9 & 10 & 7 \\
Charat Cement & 4 & 3 & 6 \\
P.S.O. & 8 & 8 & 10 \\
ICP Sems & 3 & 1 & 3 \\
Pakland Cement & 5 & 4 & 4 \\
Pak-Suzuki & 7 & 7 & 5 \\
Mohib Textile & 1 & 2 & 1 \\
Shell-Pak & 9 & 8 & 9 \\
Stand-Chartered & 10 & 9 & 7 \\
\hline
\end{tabular}

\section{CONCLUDING REMARKS}

Volatility of stock prices was found to be quite high. It ranged from a minimum of 26 percent per annum to 51 percent per annum. The existence of a strong positive correlation among the volume of trading, expected rate of return, and volatility of stock prices during the first half of 1994 indicates that the dominant trend at the Karachi Stock Exchange during this period was to invest in stocks only for short-term gains. The majority of investors entered the market when it was rising, and abandoned it when it was falling. In other words, many investors seem to follow, consciously or subconsciously, their own portfolio insurance schemes. This trend has significantly contributed to the increase in the volatility of stock prices during the period of study.

\section{REFERENCES}

Fama, E. F. (1965) The Behaviour of Stock Market Prices. Journal of Business.

French, W. (1980) Stock Returns and Weekend Effect. Journal of Financial Economics.

French, W., and E. Rolls (1986) Stock Return Variances: The Arrival of Information and the Reaction of Traders. Journal of Financial Economics. 


\section{Comments}

The paper under discussion focuses on the extremely important topic of volatility, which has received considerable attention over the past thirty years in the literature related to the study of financial markets. It is encouraging to see an attempt at modelling stock market volatility in the context of Pakistan, more specifically the Karachi Stock Exchange, since it provides a basis for comparison and evaluation of the results in the light of the existing evidence on stock market volatility for other countries. The paper is definitely a valuable addition to the meagre literature on the Pakistani stock market and will provide an impetus for further research in the area of the theory of finance and financial economics.

The authors have tried to examine the relationship of (i) stock market volatility with the volume of trading, (ii) the volume of trading and the expected rate of return, and (iii) the expected rate of return and volatility, assuming that stock prices follow a Brownian motion.

I shall focus my comments first on the methodology and then on the results.

Regarding the methodology, the authors start out by modelling the stock prices by a continuous time stochastic process. However, in the analysis they use end-of-the-week stock price data which suggests that whether or not the model could possibly have been based initially on a discrete time process such as the random walk.

Coming to the results, it would be interesting to explore more rigorously the nature of the relationship between volatility and the volume of trading in conjunction with the existing evidence on stock return variances in the finance literature. It has been established in studies of the U.S. stock exchange as well as the Japanese stock exchange that stock market prices are much more volatile during exchange trading hours than during non-trading hours. Different explanations have been put forward for this phenomenon, such as that volatility is caused by public information which is more likely to be received during business hours, or that volatility is caused by private information which affects prices when informed institutional or professional investors trade, and that volatility is caused by pricing errors that occur during trading. In short, a deeper understanding of the role of information processing and the efficiency of the trading mechanism in the stock market can be acquired by studying the effect of the time of transactions on volatility.

Another suggestion for further understanding of the concept of volatility is to explore the effect of share trading volume growth on stock market volatility.

The effect of volatility changes on the level of stock prices and subsequent expected returns have provided evidence that volatility changes have asymmetrical 
effects on stock price fluctuations. In other words, the market reacts differently to volatility increases and decreases. Since the authors of the paper report evidence of a positive association between volatility and the expected rate of return, the reaction of the level of stock prices to volatility changes could be investigated further.

In revising and extending this paper, the authors should also take into account the recent evidence on volatility in the Pakistani stock market. Using monthly data, Uppal (1993) finds evidence of international spill-over effects of volatility (especially from Korea and Japan) in the Pakistani stock market which, in his view, is suggestive of the influence of regional stock markets on volatility in the Pakistani stock market.

Another recent study by Ahmed and Rosser (1995) on the Pakistani stock market using daily data on the Karachi stock market index has tried to explain the feature of volatility using the methodology of non-linear speculative bubbles which is increasingly gaining importance in explanation of the complex dynamics of the stock markets.

Department of Economics,

Aliya H. Khan Quaid-i-Azam University, Islamabad.

\section{REFERENCES}

Ahmed, Ehsan, and J. Barkley Rosser Jr. (1995) Non-linear Speculative Bubbles in the Pakistani Stock Market. The Pakistan Development Review 34:1 25-41.

Uppal, Jamshed Y. (1993) The Internationalisation of the Pakistani Stock Market: An Empirical Investigation. The Pakistan Development Review 32:4 605-618. 